\title{
Effect of intrawound vancomycin application in spinal surgery on the incidence of surgical site infection: a meta-analysis
}

This article was published in the following Dove Press journal:

Therapeutics and Clinical Risk Management

\begin{abstract}
Abuduwufuer Tailaitil,*
Jun Shang 2 **

Shuo Shan ${ }^{3}$

Aikeremujiang Muheremu ${ }^{4}$

'Department of Orthopedic Surgery, Urumqi Friendship Hospital, Xinjiang 86830049, China; ${ }^{2}$ Department of Orthopedics, People's Hospital of Linfen, Shanxi, 86041000, China; ${ }^{3}$ Department of Spine Surgery, Traditional Chinese Hospital Affiliated With Xinjiang Medical University, Xinjiang 86830000, China; ${ }^{4}$ Department of Spine Surgery, Sixth Affiliated Hospital of Xinjiang Medical University, Urumqi, Xinjiang 8683000I, China
\end{abstract}

*These authors contributed equally to this work

Correspondence: Aikeremujiang Muheremu

Institute of Orthopaedics, General Hospital of People's Liberation Army, NO28 Fuxing Rd, Haidian District, Beijing, 86I00853, China

Tel +86 I88 109I 4750

Email akrammuharram@I63.com
Background: Despite great advances in aseptic surgical techniques, surgical site infection (SSI) is still one of the main complications after spine surgery. SSI can bring tremendous physical, psychological, and economic challenges to patients. Intrawound vancomycin application is a much disputed method for the prevention of SSI after spine surgery.

Objective: The aim of this study is to review the current literature for studies on the intrawound application of vancomycin powder and to analyze its effectiveness in the prevention of postoperative SSI.

Methods: PubMed, Medline, Elsevier, and CNKI were searched for the key words "vancomycin", "local/intraoperative/topical/intra-wound", "spine/spinal/lumbar/cervical/thoracolumbar surgery", "infection", and "SSI" in published studies on the effectiveness of intrawound vancomycin application to prevent postoperative SSI. RevMan 5.3 was used to compare the data extracted from the studies included.

Results: A total of 27 studies involving 17,321 patients were included in the final analysis. Among those patients, 7,423 patients were treated with vancomycin to prevent SSI, with 9,898 in control groups. SSI incidence after surgery in experimental groups was 0.39 times as high as control groups, and this difference was statistically significant $(P<0.01)$. Among patients who underwent internal fixation, vancomycin application significantly reduced the incidence of postoperative SSI (OR 0.31 $95 \%$ CI 0.19-0.50; $P<0.01)$. Meanwhile, vancomycin did not affect SSI incidence in patients who did not receive internal fixation $(P=0.17)$ or received deformity correction $(P=0.25)$.

Conclusion: SSI incidence after spinal surgery can be significantly reduced by intrawound application of vancomycin in most circumstances. This method can be applied in various spinal procedures involving instrumentation to prevent postoperative SSI.

Keywords: spinal surgery, vancomycin, intrawound, surgical site infection, prevention, metaanalysis

\section{Background}

Despite highly developed intraoperative aseptic techniques, postoperative surgical site infection (SSI) is still one of the most common complications of spine surgery. In the current literature, SSI incidence after spine surgery ranges $2 \%-13 \%{ }^{1,2}$ In US, there are half a million patents with SSI, and the direct cost for treatment is as high as $\$ 1.8$ billion annually. ${ }^{3}$ For patients, SSI brings about an average of 2 weeks longer in hospital, higher medical bills, and increased likelihood of disability, mortality, and physical and physiological pressure. ${ }^{4}$

Now that SSI prevention is one of the main requirements of high-standard medical centers, numerous techniques and guidelines have been developed to avoid it. ${ }^{5,6}$ 
After Buchholz et $\mathrm{al}^{41}$ applied antibiotics at the site of surgery to prevent SSI and gained satisfying results, a variety of antibiotics were tried regionally for the same purposes. ${ }^{7,8}$ In consideration of the fact that the main pathogens in SSI are Staphylococcus aureus and Staphylococcus epidermidis and that vancomycin can eliminate both, its local application may significantly decrease SSI after spinal surgery. In the last decade, there have been numerous studies on the local application of vancomycin powder on the surgical site, but results of those studies are controversial. As such, the current study was carried out to assess the results of those studies and provide guidance for future clinical practice.

\section{Methods}

\section{Literature search}

Two independent reviewers carried out computerized search of the databases PubMed (2005-2018), Medline (2005-2018), Embase (2005-2018), Elsevier (2005-2018), Cochrane library (2008-2018), and CNKI (2005-2018) with the MeSH words "vancomycin", "local/intraoperative/ topical/intra-wound", "spine/spinal/lumbar/cervical/thoracolumbar surgery", "infection", and "SSI". Where the two authors disagreed on whether studies had met the inclusion criteria, a neutral scholar was invited to settle the disputes. Two authors independently assessed the quality of the studies included with the Newcastle-Ottawa Scale (NOS). ${ }^{9}$

\section{Data extraction}

Data from the trails were extracted by two independent reviewers. The authors of each study, study design, sample size, patient age, time of study, and intervention methods were extracted as basic demographic data. Overall patient numbers, number of patients who had had vancomycin applied regionally to prevent postoperative SSI, and number of patients with SSI were recorded as outcome parameters. In cases where the same patients were analyzed in more than one study, they were extracted and analyzed as one patient population.

\section{Analysis}

Data were analyzed and processed using RevMan 5.3 (Cochrane Collaboration, Oxford, UK). Two authors checked data input to make sure that no errors were made. Studies were considered to have significant heterogeneity if $I^{2}>50 \%$, in which case random-effect analysis was performed on the study data. Differences in each study were defined by OR with 95\% CI for categorical outcome frequencies in study groups and control groups. ORs for all trials are shown in forest plots.

\section{Results Study selection}

Among a total of 1,715 studies, 27 studies $^{10-36}$ comparing the effectiveness of vancomycin in preventing SSI after spine surgery were included in the final analysis. Those studies reported the outcome of 17,321 patients with or without the regional application of vancomycin after spinal surgery. Vancomycin was applied in 7,423 of those patients and not applied in 9,898 patients (Figure 1; Table 1).

In the 27 studies included, two were randomized controlled trials (RCTs) and the remaining were retrospective cohort studies. They were carried out between 2011 and 2018 and mostly between 2013 and 2015. The level of evidence in studies was 2-3, with NOS scores of 5-7 (Table 1).

\section{Overall analysis}

The meta-analysis on the overall effect of vancomycin on SSI included a total number of 17,321 patients. Vancomycin was applied in 7,423 of those patients, while vancomycin was not applied in 9,898 patients. Random-effect analysis was carried out because $I^{2}>50 \%$. Results of the meta-analysis indicated that SSI incidence in control groups (no vancomycin) was 2.56 times as high as in experimental groups (vancomycin applied locally during surgery). The difference was significant between the groups $(P<0.01$; Figure 2$)$.

\section{Subgroup analysis according to the study design}

In consideration of the fact that results of RCTs may have less patient selection bias than retrospective studies, here, we meta-analyzed the data by RCTs and retrospective studies separately. In the current literature, there are only two RCTs: studies by Tukabi et al and Mirzashahi et al. Those studies included a total of 1,287 patients, and meta-analysis indicated that SSI incidence in vancomycin groups was 1.36 times as high as in control groups (95\% CI 0.65-2.83), but this difference was not significant $(P=0.41)$. Meanwhile, meta-analysis of 25 retrospective studies with 16,034 patients indicated that SSI incidence in vancomycin groups was 0.34 times as high as in the control group (95\% CI 0.23-0.51), and this difference was significant $(P<0.01$; Figure 3$)$. Given that neither of the RCTs provided a trial registration number and both were carried out in a single study center, the quality control status of those RCTs may be questionable. More 


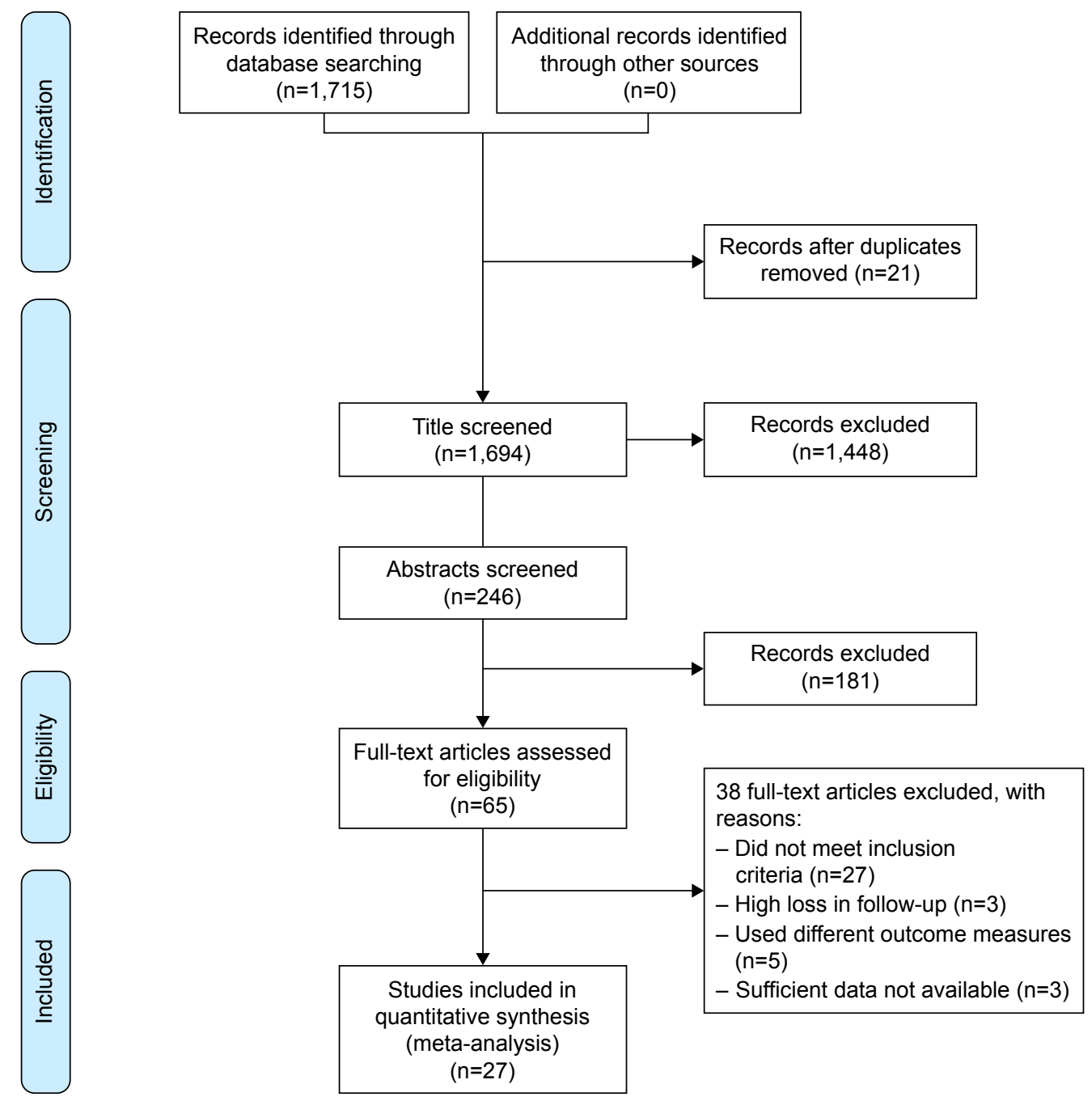

Figure I Selection of papers for this research. A total of 27 studies were included in the final analysis.

multicenter RCTs with strict quality control are necessary to reach a more reliable result.

\section{Subgroup analysis according to the application of internal fixation}

In consideration of the fact that patients with internal fixation may face higher likelihood of SSI after surgery, in the current study, we analyzed patients who underwent internal fixation and those who did not separately. In the 18 studies included in this analysis, 7,776 patients received internal fixation. Metaanalysis indicated that SSI incidence in vancomycin groups is 0.31 times as high as control groups ( $95 \%$ CI $0.19-0.50$ ), and this difference was significant $(P<0.01)$. The analysis of four studies including 560 patients indicated that when no instrumentation was applied, SSI incidence in vancomycin groups was 0.19 times as high as in control groups $(95 \% \mathrm{CI}$ $0.02-2.03)$, but this difference was not significant $(P=0.12)$.
This indicated that the local application of vancomycin may not affect SSI incidence in patients with no internal fixation (Figure 4).

\section{Subgroup analysis of deformity correction or nondeformity correction surgery}

Patients who undergo deformity correction surgery always have to endure longer operations, more intraoperative hemorrhage, and more implants than in conventional spine surgeries. All those factors can increase the possibility of postoperative SSI. In the current study, four studies including 1,250 subjects were on patients who underwent spinal deformity correction. Meta-analysis of these studies showed that in spinal deformity surgeries, the SSI possibility in vancomycin groups was 0.59 times as much as no-vancomycin groups (95\% CI $0.24-0.1 .43)$, but this difference was not significant $(P=0.06)$. Meanwhile, meta-analysis of 

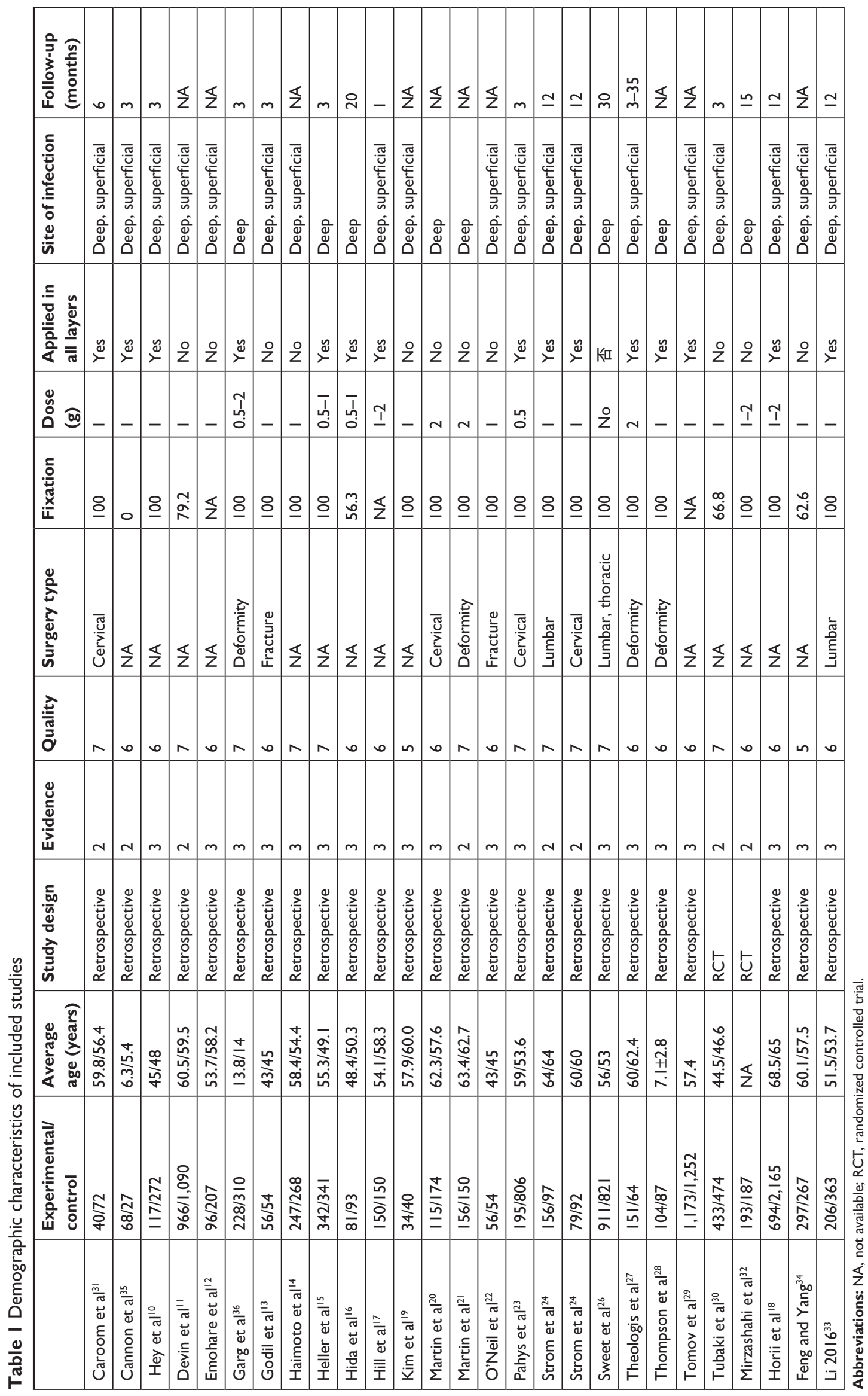


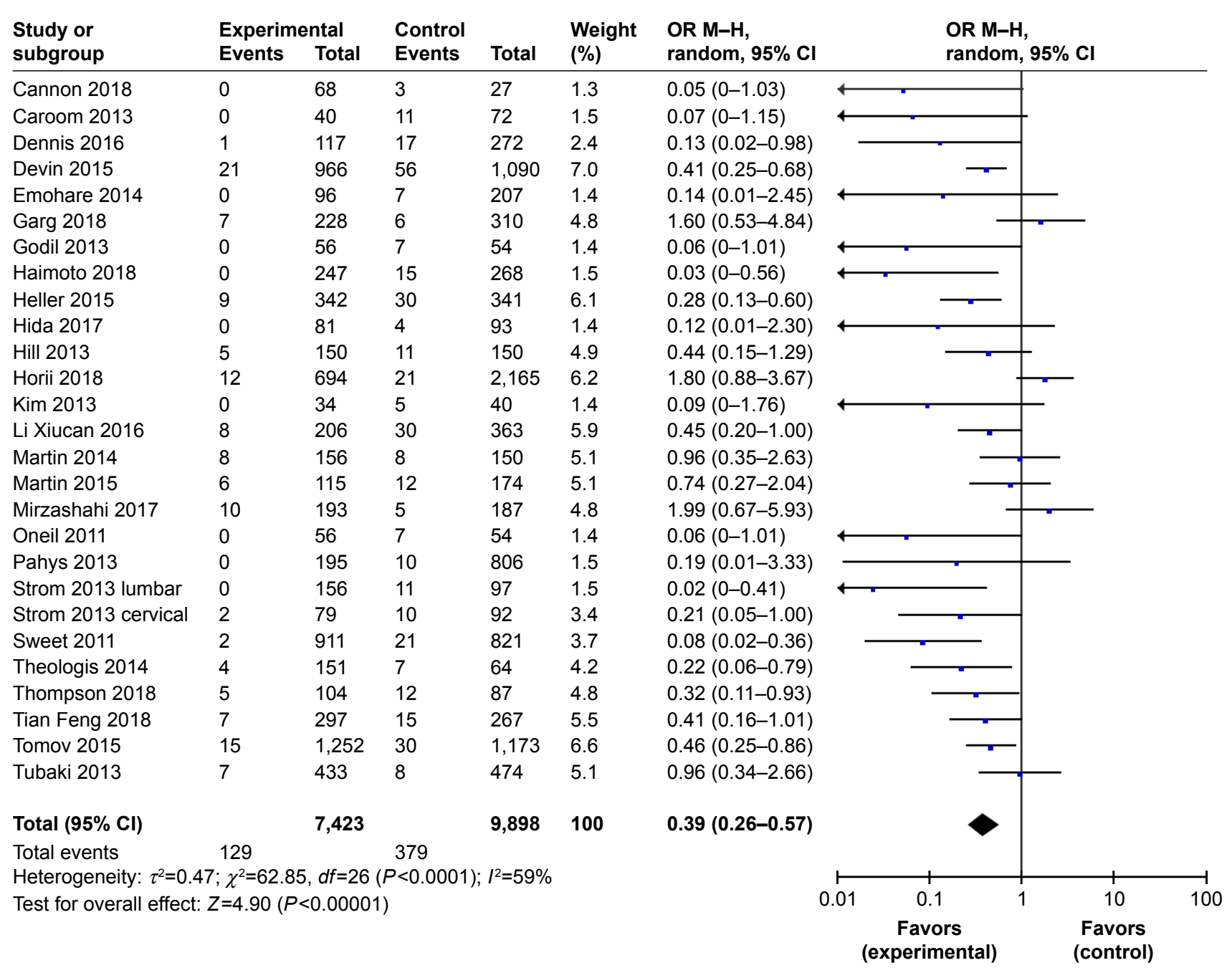

Figure 2 Overall surgical site infection incidence was significantly low when vancomycin was applied locally after surgery $(P<0.01)$.

23 studies with 16,071 patients who did not underwent spinal deformity-correction surgery showed that vancomycin group has 0.35 times as much SSI possibility as no-vancomycin group (95\% CI 0.23-0.53). This difference was significant $(P<0.01$; Figure 5).

\section{Subgroup analysis depending on the site of surgery}

In consideration of the fact that there could be differences in SSI incidence in patients undergoing cervical, thoracic, or lumbar surgery, in the current study, we analyzed patients who received surgical treatment on cervical, thoracic, or lumbar region separately. Given that the studies included did not provide adequate information on patients receiving thoracic spine surgery and that most surgeries carried out on the thoracic region also involve the thoracolumbar junction, in the current study, we analyzed the data of thoracic and lumbar regions as a whole. Among the studies included, five studies with 1,684 patients received surgical treatment in the cervical region. Meta-analysis indicated that SSI incidence in vancomycin groups was 0.33 times as high as control groups (95\% CI 0.16-0.69), and this difference was significant $(P<0.01)$. The analysis of four studies including 3,118 patients who received surgical treatment in the thoracic and lumbar regions indicated that SSI incidence in vancomycin groups was 0.27 times as high as control groups (95\% CI 0.08-0.85), and this difference was also significant $(P=0.03)$. This indicated that local application of vancomycin can significantly reduce SSI incidence in patients who receive surgical treatment in the cervical, thoracic, or lumbar region (Figure 6).

\section{Effect of vancomycin on deep and superficial infection after spine surgery}

In consideration of the fact that deep and superficial infections after spine surgery require different treatment options 


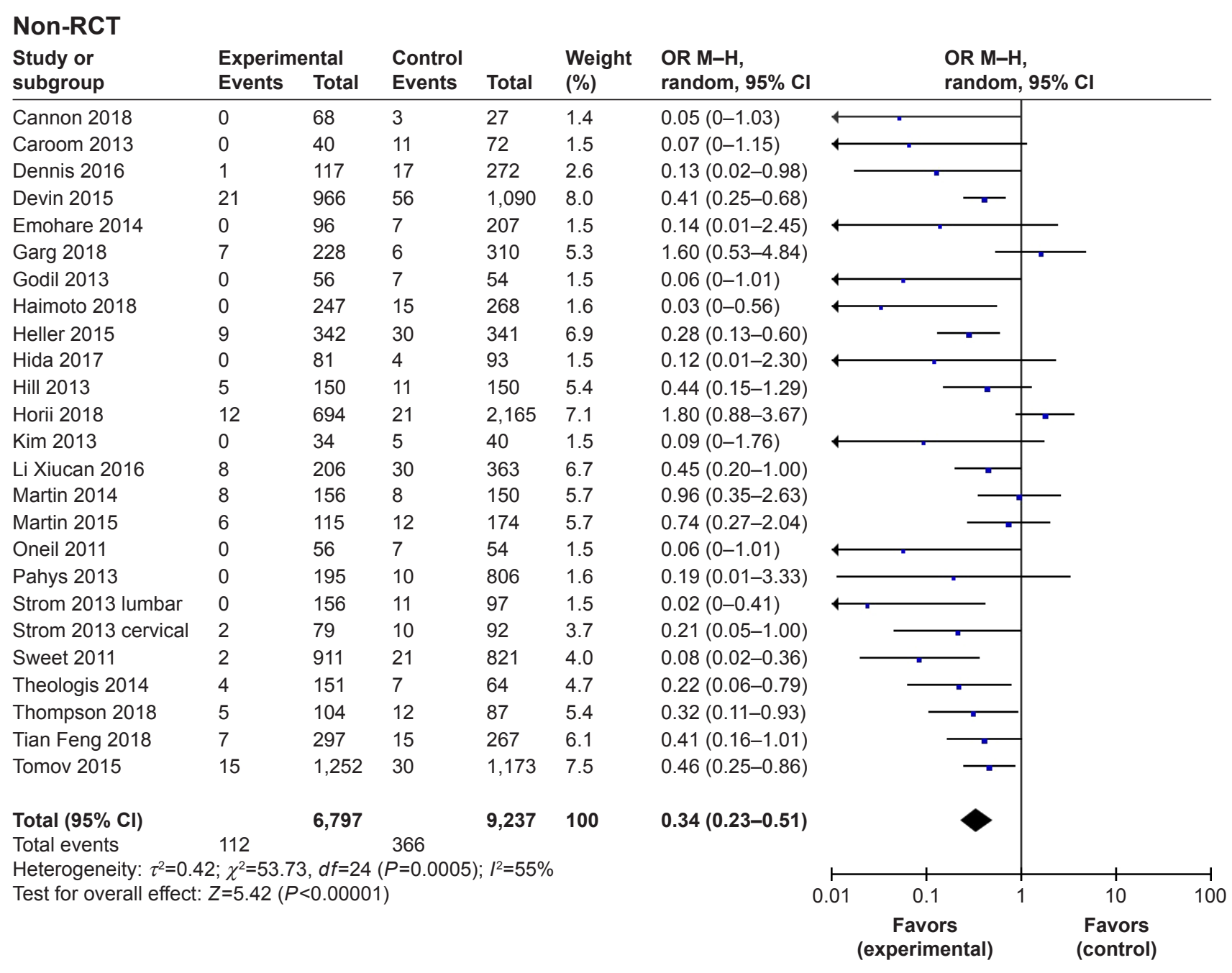

\section{RCT}

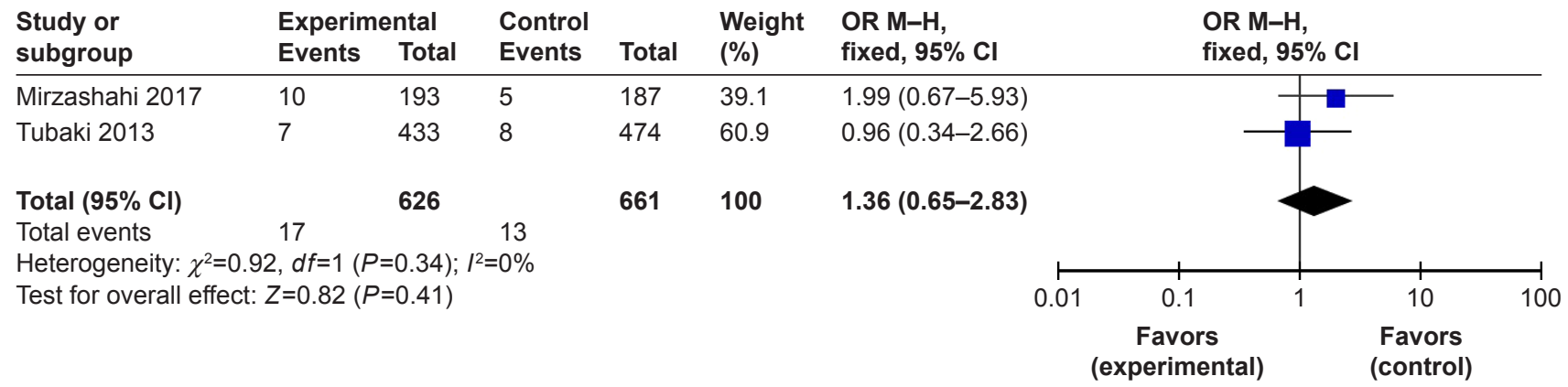

Figure 3 Meta-analysis of randomized controlled trials (RCTs) and retrospective studies.

and have different outcomes, we analyzed the incidence of deep and superficial infections between the two groups. Eight studies including 4,532 patients analyzed the incidence of deep tissue infection after spinal surgery, which was lower in the vancomycin group than in the no-vancomycin group (OR $=0.39,95 \%$ CI $0.16-0.98 ; P=0.05)$. In the meanwhile, the analysis of five studies including 1,973 patients revealed that application of vancomycin did not significantly reduce the incidence of superficial wound infection (OR 0.83, 95\% CI $0.40-1.71 ; P=0.62$; Figure 7).

\section{Discussion}

With advances in aseptic surgical techniques, postoperative SSI incidence is gradually decreasing. However, SSI is still one of the most common surgery-related complications. In the current literature, the incidence of SSI is as high as $10 \%{ }^{37}$ 


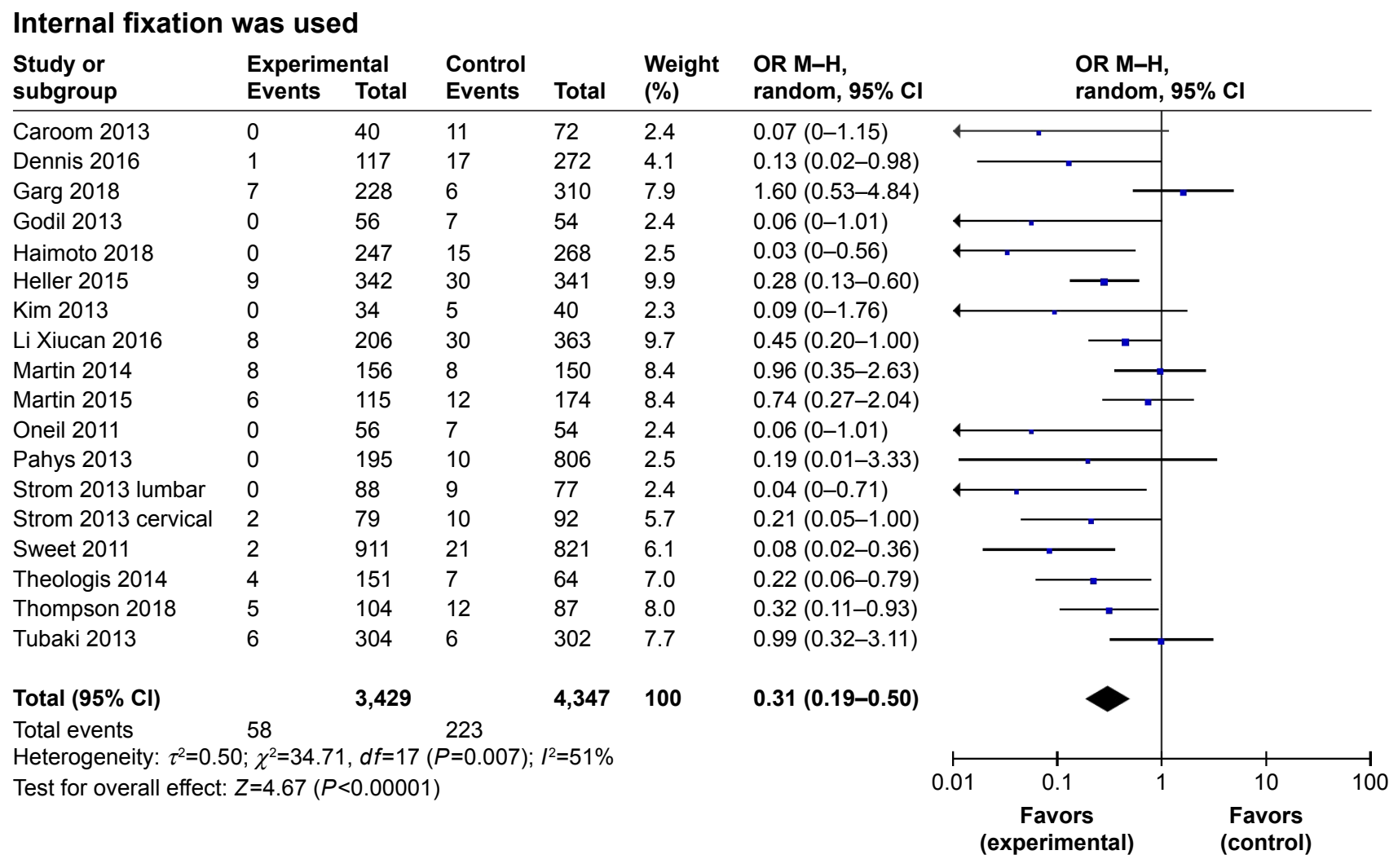

Internal fixation was not used

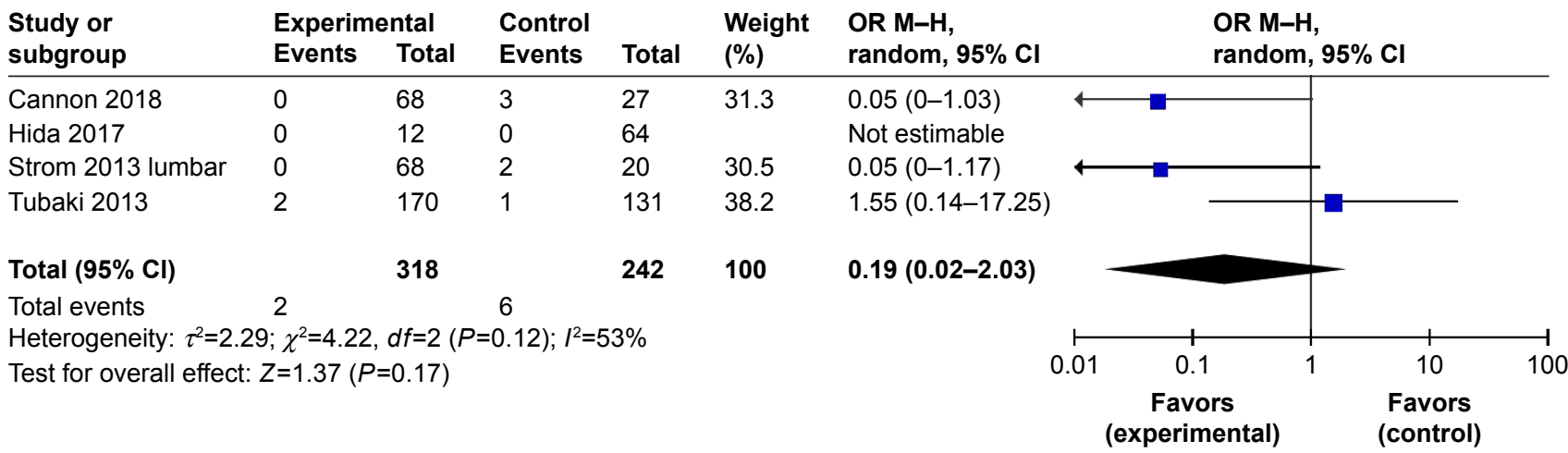

Figure 4 Local application of vancomycin reduced surgical site infections after surgery irrespective of whether internal fixation was used.

Risk factors for SSI include being overweight, overage, diabetes, smoking, poor overall physical condition, implant application, long surgery, and voluminous hemorrhage. ${ }^{38}$

Vancomycin has been proven to be effective in reducing postoperative SSI in patients undergoing arthroplasty. ${ }^{39}$ Intravenous application of vancomycin can affect liver and kidney functions. Compared to intravenous drug delivery, local application of vancomycin powder can reach high doses specific to the surgical region, avoiding injury to healthy organs. ${ }^{40}$ Therefore, regional application of vancomycin powder may reduce SSI after spine surgery without causing serious harmful effects to vital organs. In the last two decades, vancomycin has been applied in several medical centers. However, the results are controversial. The current research was carried out to assess the published studies and provide more reliable information for future clinical work.

In our literature research, we found 27 studies including 17,321 patients on the effectiveness and safety of vancomycin. This is the meta-analysis with the largest participant base so far. Result of the current meta-analysis showed that the regional application of vancomycin could reduce SSI incidence to approximately one-third (OR 0.39) of that when vancomycin was not applied. The difference between the two groups was significant $(P<0.00001)$. 


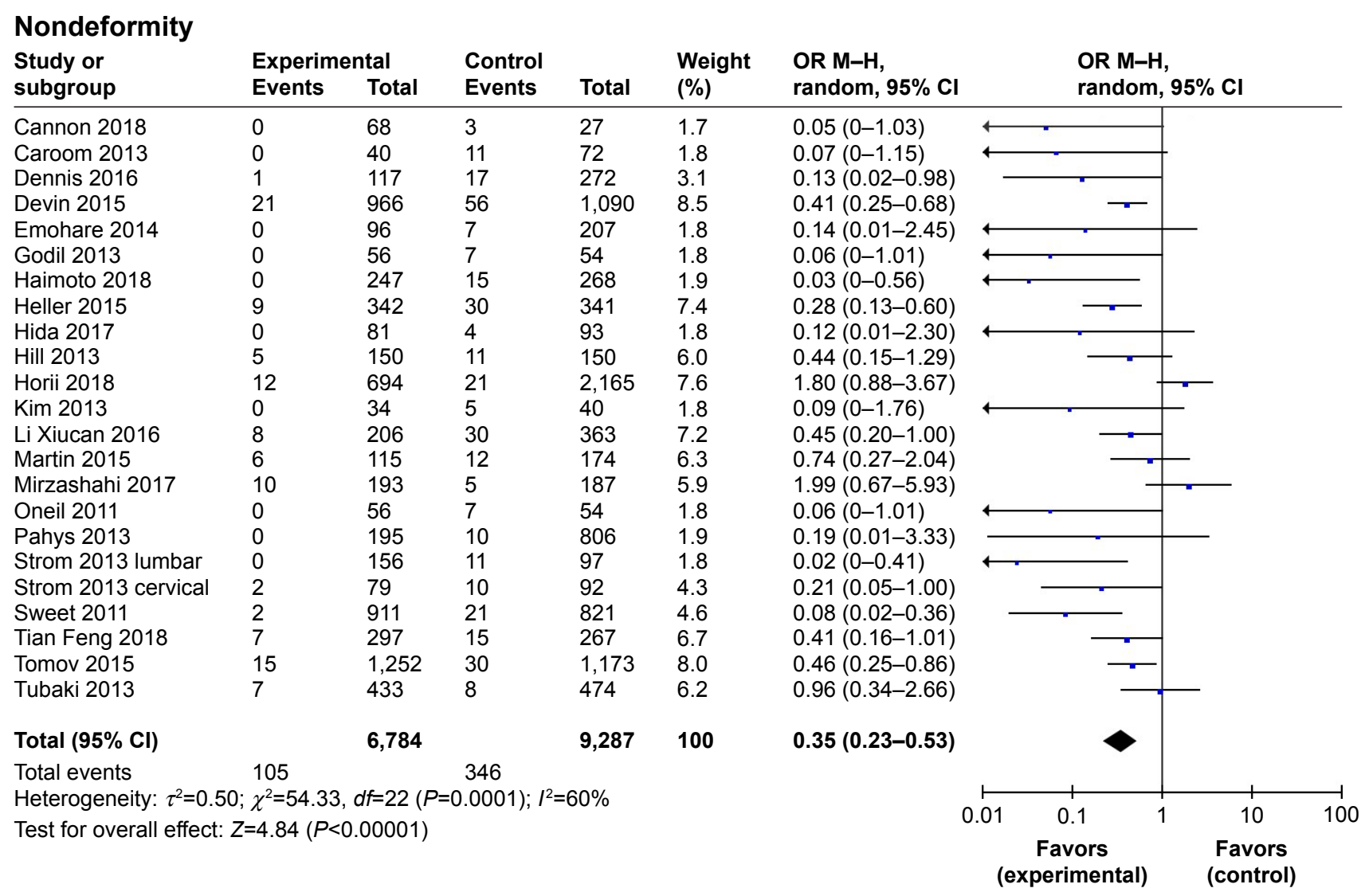

\section{Deformity}

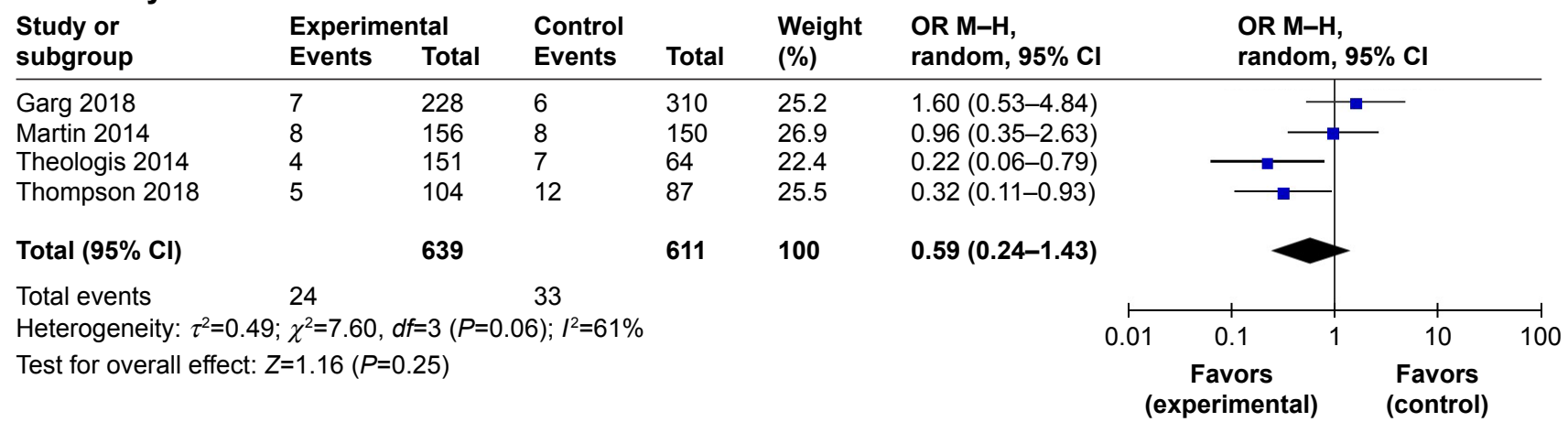

Figure $\mathbf{5}$ Local application of vancomycin reduced surgical site infections after surgery in both spinal deformity surgeries and nondeformity surgeries.

17,321 patients received a variety of surgical treatments, including spinal deformity surgery and common surgery with or without internal fixation. In consideration of the fact that different treatment measures may react differently to the application of vancomycin, we analyzed patients by the surgical treatment they received. Vancomycin was proven to be effective in reducing SSI after all varieties of spinal surgeries, except when instrumentation was not applied $(P=0.17)$ and in deformity correction surgery $(P=0.25)$. However, because of the vague information in most publications, there were only four studies with 560 patients that reported not using any implants, and only eight of those patients suffered from SSI. On the other hand, there were 7,776 patients in 18 studies in the meta-analysis showing that the application of vancomycin can significantly reduce SSI after spine surgery (OR 0.31, 95\% CI 0.19-0.50). These results indicate that in patients with no instrumentation, it may not be necessary to use vancomycin to prevent SSI, but still more data can be used to solidify this conclusion.

Similarly, there were only four studies with 1,250 patients leading to the conclusion that vancomycin may not help to decrease SSI in deformity correction surgery. This result 


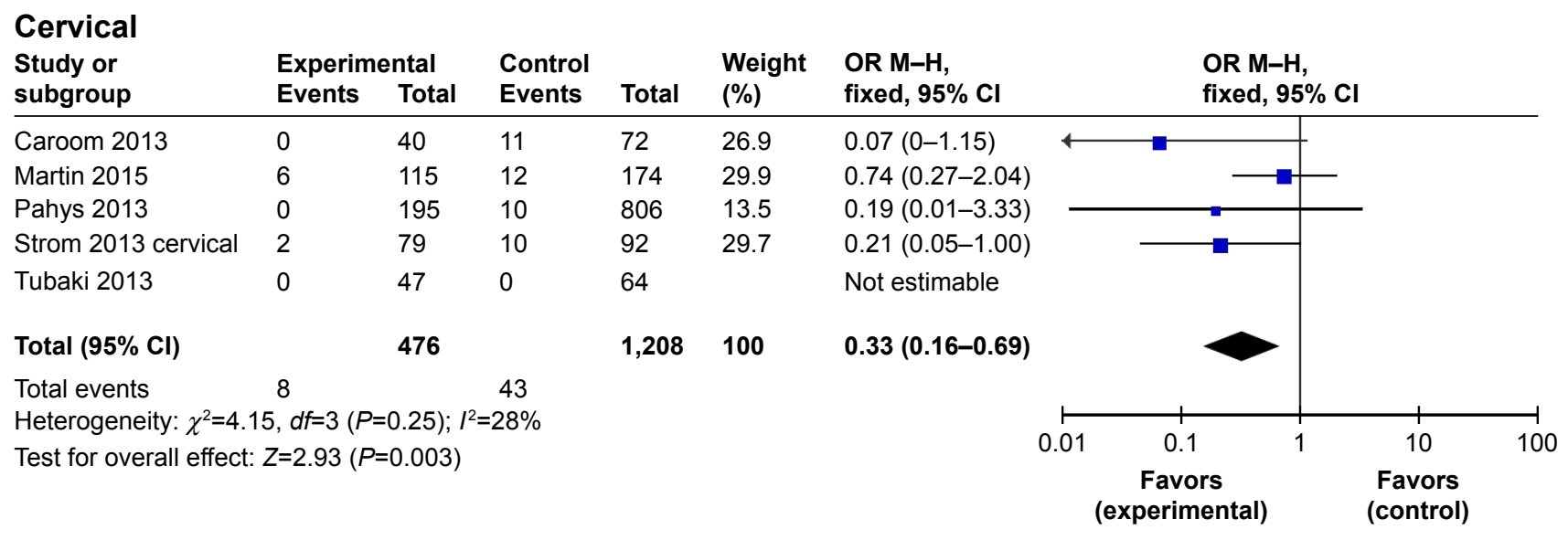

Thoracic, lumbar

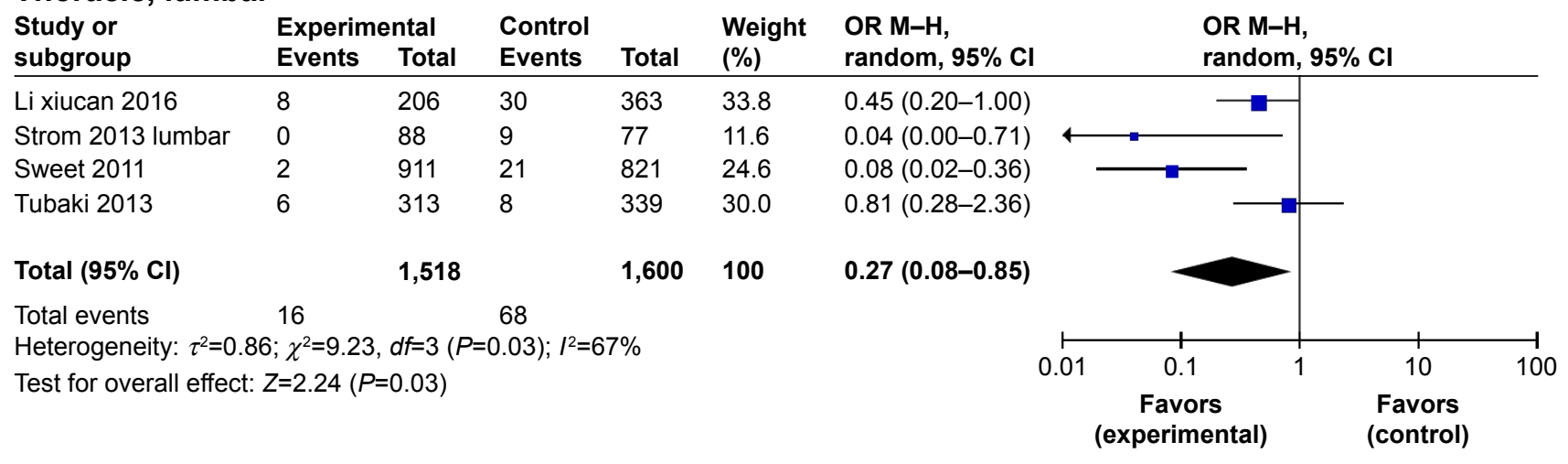

Figure 6 Local application of vancomycin significantly reduced surgical site infection incidence in patients who received cervical, thoracic, or lumbar surgical treatment.

could change with more data from the studies that had strict design and large sample. It can also be seen from the current research that although the incidence of deep wound infection may be influenced by the application of vancomycin (OR $0.39,95 \%$ CI $0.16-0.98 ; P=0.05)$, the incidence of superficial wound infection may not be influenced by the application of vancomycin (OR 0.83 , 95\% CI 0.40-1.71; $P=0.62$ ). However, since deep wound infection can be much more harmful to patients and more difficult to treat, it is still plausible to use vancomycin intraoperatively to prevent SSI.

\section{Deep}

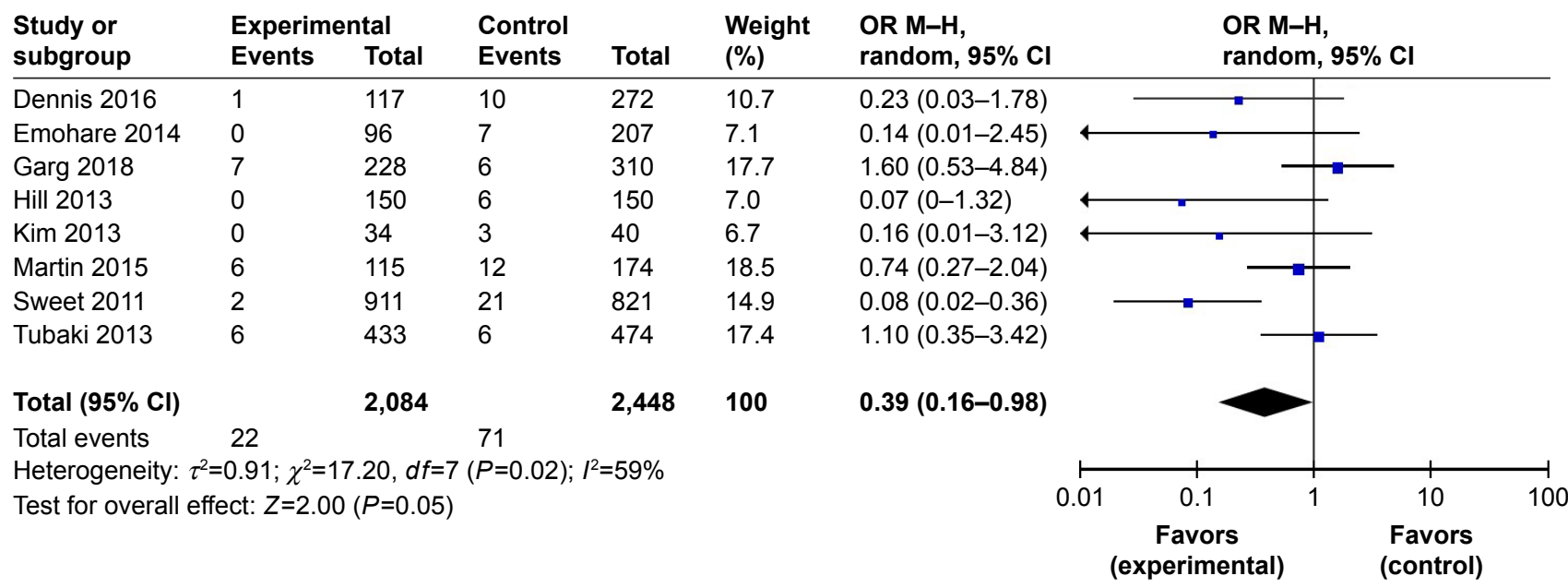

Figure 7 (Continued) 


\section{Superficial}

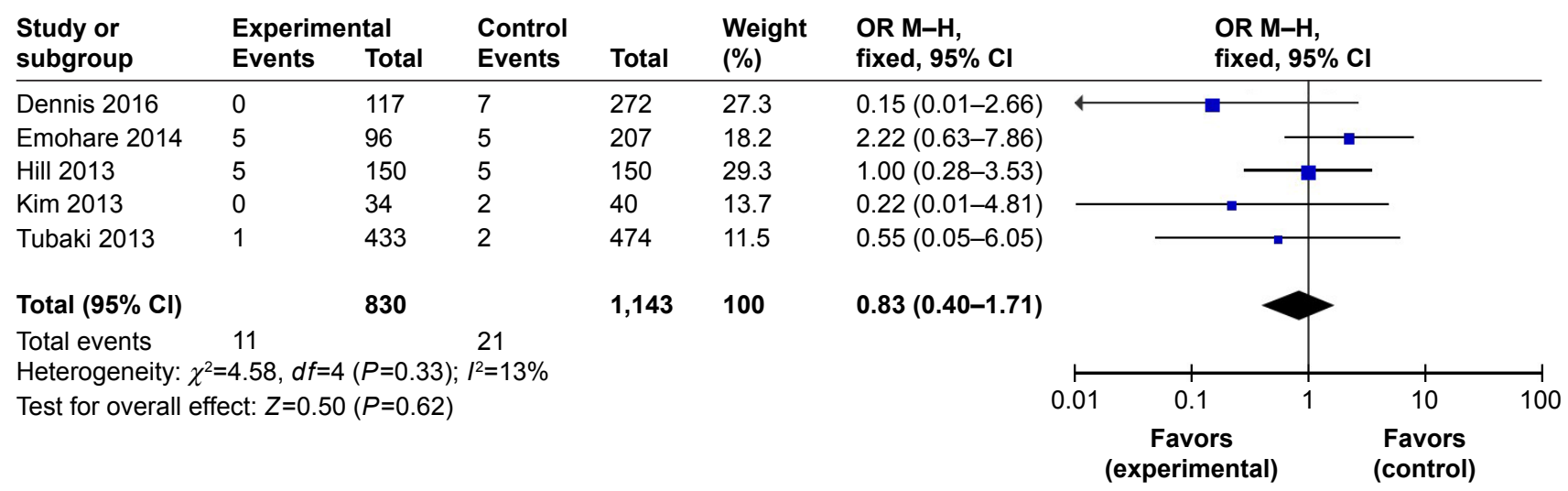

Figure 7 Subgroup analysis of incidence of deep (upper) and superficial (lower) tissue infections after spinal surgeries.

The current study has several disadvantages. Among the 27 included studies, only two studies were RCTs, with the rest being retrospective cohort studies. Most studies included 300-1,000 patients, with four exceptional studies with $>1,000$ participants. Considering that NOS scores of those studies were mostly 6-7, we included them in the data extraction process and used random-effect analysis when $I^{2}>50 \%$. Therefore, we believe the final data are still meaningful for clinical practice. However, due to the study design in most retrospective studies, there were few patients with no-instrumentation treatment. Results of the meta-analysis may change with more RCTs with more strict design and execution.

\section{Conclusion}

SSI incidence after spinal surgery can be significantly reduced by intrawound application of vancomycin in most circumstances. This method can be applied with instrumentation in various clinical settings of spine practice, except for no-instrumentation surgery, to prevent postoperative SSI.

\section{Disclosure}

The authors alone are responsible for the content and writing of the article. The authors report no conflicts of interest in this work.

\section{References}

1. Bakhsheshian J, Dahdaleh NS, Lam SK, Savage JW, Smith ZA. The use of vancomycin powder in modern spine surgery: systematic review and meta-analysis of the clinical evidence. World Neurosurg. 2015; 83(5):816-823.

2. Khan NR, Thompson CJ, DeCuypere M, et al. A meta-analysis of spinal surgical site infection and vancomycin powder. J Neurosurg Spine. 2014; 21(6):974-983.

3. Awad SS. Adherence to surgical care improvement project measures and post-operative surgical site infections. Surg Infect (Larchmt). 2012;13(4): 234-237.
4. McGirt MJ, Godil SS. Reduction of surgical site infection in spine surgery: an opportunity for quality improvement and cost reduction. Spine J. 2013;13(9):1030-1031.

5. Olsen MA, Nepple JJ, Riew KD, et al. Risk factors for surgical site infection following orthopaedic spinal operations. J Bone Joint Surg Am. 2008;90(1):62-69.

6. Savage JW, Anderson PA. An update on modifiable factors to reduce the risk of surgical site infections. Spine J. 2013;13(9):1017-1029.

7. Kanj WW, Flynn JM, Spiegel DA, Dormans JP, Baldwin KD. Vancomycin prophylaxis of surgical site infection in clean orthopedic surgery. Orthopedics. 2013;36(2):138-146.

8. Mohammed S, Pisimisis GT, Daram SP, et al. Impact of intraoperative administration of local vancomycin on inguinal wound complications. J Vasc Surg. 2013;57(4):1079-1083.

9. Stang A. Critical evaluation of the Newcastle-Ottawa scale for the assessment of the quality of nonrandomized studies in meta-analyses. Eur J Epidemiol. 2010;25(9):603-605.

10. Hey HW, Thiam DW, Koh ZS, et al. Is Intraoperative Local Vancomycin Powder the Answer to Surgical Site Infections in Spine Surgery? Spine (Phila Pa 1976). 2017;42(4):267-274.

11. Devin CJ, Chotai S, McGirt MJ, et al. Intrawound vancomycin decreases the risk of surgical site infection after posterior spine surgery: a multicenter analysis. Spine (Phila Pa 1976). 2018;43(1): 65-71.

12. Emohare O, Ledonio CG, Hill BW, Davis RA, Polly DW Jr, Kang MM. Cost savings analysis of intrawound vancomycin powder in posterior spinal surgery. Spine J. 2014;14(11):2710-2715.

13. Godil SS, Parker SL, O’Neill KR, Devin CJ, McGirt MJ. Comparative effectiveness and cost-benefit analysis of local application of vancomycin powder in posterior spinal fusion for spine trauma: clinical article. J Neurosurg Spine. 2013;19(3):331-335.

14. Haimoto S, Schär RT, Nishimura Y, Hara M, Wakabayashi T, Ginsberg HJ. Reduction in surgical site infection with suprafascial intrawound application of vancomycin powder in instrumented posterior spinal fusion: a retrospective case-control study. J Neurosurg Spine. 2018;29(2):193-198.

15. Heller A, McIff TE, Lai SM, Burton DC. Intrawound vancomycin powder decreases staphylococcal surgical site infections after posterior instrumented spinal arthrodesis. J Spinal Disord Tech. 2015; 28(10):E584-E589.

16. Hida T, Ando K, Kobayashi K, et al. Intrawound Vancomycin powder as the prophylaxis of surgical site infection after invasive spine surgery with a high risk of infection. Nagoya J Med Sci. 2017;79(4): 545-550.

17. Hill BW, Emohare O, Song B, Davis R, Kang MM. The use of vancomycin powder reduces surgical reoperation in posterior instrumented and noninstrumented spinal surgery. Acta Neurochir (Wien). 2014;156(4): $749-754$. 
18. Horii C, Yamazaki T, Oka H, et al. Does intrawound vancomycin powder reduce surgical site infection after posterior instrumented spinal surgery? A propensity score-matched analysis. Spine J. Epub 2018 Apr 26.

19. Kim HS, Lee SG, Kim WK, Park CW, Son S. Prophylactic intrawound application of vancomycin powder in instrumented spinal fusion surgery. Korean J Spine. 2013;10(3):121-125.

20. Martin JR, Adogwa O, Brown CR, et al. Experience with intrawound vancomycin powder for posterior cervical fusion surgery. J Neurosurg Spine. 2015;22(1):26-33.

21. Martin JR, Adogwa O, Brown CR, et al. Experience with intrawound vancomycin powder for spinal deformity surgery. Spine (Phila Pa 1976). 2014;39(2):177-184.

22. O’Neill KR, Smith JG, Abtahi AM, et al. Reduced surgical site infections in patients undergoing posterior spinal stabilization of traumatic injuries using vancomycin powder. Spine J. 2011;11(7):641-646.

23. Pahys JM, Pahys JR, Cho SK, et al. Methods to decrease postoperative infections following posterior cervical spine surgery. J Bone Joint Surg Am. 2013;95(6):549-554.

24. Strom RG, Pacione D, Kalhorn SP, Frempong-Boadu AK. Lumbar laminectomy and fusion with routine local application of vancomycin powder: decreased infection rate in instrumented and non-instrumented cases. Clin Neurol Neurosurg. 2013;115(9):1766-1769.

25. Strom RG, Pacione D, Kalhorn SP, Frempong-Boadu AK. Decreased risk of wound infection after posterior cervical fusion with routine local application of vancomycin powder. Spine (Phila Pa 1976). 2013;38(12):991-994.

26. Sweet FA, Roh M, Sliva C. Intrawound application of vancomycin for prophylaxis in instrumented thoracolumbar fusions: efficacy, drug levels, and patient outcomes. Spine (Phila Pa 1976). 2011;36(24):2084-2088

27. Theologis AA, Demirkiran G, Callahan M, Pekmezci M, Ames C, Deviren V. Local intrawound vancomycin powder decreases the risk of surgical site infections in complex adult deformity reconstruction: a cost analysis. Spine (Phila Pa 1976). 2014;39(22):1875-1880.

28. Thompson GH, Poe-Kochert C, Hardesty CK, Son-Hing J, Mistovich RJ. Does Vancomycin Powder Decrease Surgical Site Infections in Growing Spine Surgery?: A Preliminary Study. J Bone Joint Surg Am. 2018; 100(6):466-471.

29. Tomov M, Mitsunaga L, Durbin-Johnson B, Nallur D, Roberto R. Reducing surgical site infection in spinal surgery with betadine irrigation and intrawound vancomycin powder. Spine (Phila Pa 1976). 2015; 40(7):491-499.
30. Tubaki VR, Rajasekaran S, Shetty AP. Effects of using intravenous antibiotic only versus local intrawound vancomycin antibiotic powder application in addition to intravenous antibiotics on postoperative infection in spine surgery in 907 patients. Spine (Phila Pa 1976). 2013;38(25):2149-2155.

31. Caroom C, Tullar JM, Benton EG Jr, Jones JR, Chaput CD. Intrawound vancomycin powder reduces surgical site infections in posterior cervical fusion. Spine (Phila Pa 1976). 2013;38(14):1183-1187.

32. Mirzashahi B, Chehrassan M, Mortazavi SMJ. Intrawound application of vancomycin changes the responsible germ in elective spine surgery without significant effect on the rate of infection: a randomized prospective study. Musculoskelet Surg. 2018;102(1):35-39.

33. Li XC, Qin Y, Xuxuan W, Wang XX. The effect of local application of vancomycin powder after posterior lumbar interbody fusion surgery on prevention of surgical site infection and fusion rate. Chin J Spine Spinal Cord. 2016;26(12):1109-1114.

34. Feng T, Yang Y. Effects observation of local intrawound application vancomycin in prevention surgical site infection after the spine surgeries. J Clin Orthop. 2018;21(2):157-159.

35. Cannon JGD, Ho AL, Mohole J, et al. Topical vancomycin for surgical prophylaxis in non-instrumented pediatric spinal surgeries. Childs Nerv Syst. 2018;5:1-5.

36. Garg S, Bloch N, Potter M, et al. Topical vancomycin in pediatric spine surgery does not reduce surgical site infection: a retrospective cohort study. Spine Deform. 2018;6(5):523-528.

37. Sasso RC, Garrido BJ. Postoperative spinal wound infections. J Am Acad Orthop Surg. 2008;16(6):330-337.

38. Gerometta A, Rodriguez Olaverri JC, Bitan F. Infections in spinal instrumentation. Int Orthop. 2012;36(2):457-464.

39. Saleh A, Khanna A, Chagin KM, Klika AK, Johnston D, Barsoum WK. Glycopeptides versus $\beta$-lactams for the prevention of surgical site infections in cardiovascular and orthopedic surgery: a meta-analysis. Ann Surg. 2015;261(1):72-80.

40. Evaniew N, Khan M, Drew B, Peterson D, Bhandari M, Ghert M. Intrawound vancomycin to prevent infections after spine surgery: a systematic review and meta-analysis. Eur Spine J. 2015;24(3):533-542.

41. Buchholz HW, Elson RA, Engelbrecht E, et al. Management of deep infection of total hip replacement. J Bone Joint Surg Br. 1981;63(3): $342-353$.
Therapeutics and Clinical Risk Management

\section{Publish your work in this journal}

Therapeutics and Clinical Risk Management is an international, peerreviewed journal of clinical therapeutics and risk management, focusing on concise rapid reporting of clinical studies in all therapeutic areas outcomes, safety, and programs for the effective, safe, and sustained use of medicines. This journal is indexed on PubMed Central, CAS,

\section{Dovepress}

EMBase, Scopus and the Elsevier Bibliographic databases. The manuscript management system is completely online and includes a very quick and fair peer-review system, which is all easy to use. Visit http://www.dovepress.com/testimonials.php to read real quotes from published authors. 